\title{
Electrophysiological characterization of male goldfish (Carassius auratus) ventral preoptic area neurons receiving olfactory inputs
}

\author{
Wudu E. Lado ${ }^{1,2}$, David C. Spanswick ${ }^{3,4}$, John E. Lewis ${ }^{1}$ and Vance L. Trudeau ${ }^{1 *}$ \\ 1 Department of Biology, University of Ottawa, Ottawa, ON, Canada \\ 2 Department of Cell and Systems Biology, University of Toronto, Toronto, ON, Canada \\ ${ }^{3}$ Warwick Medical School, University of Warwick, Coventry, UK \\ ${ }^{4}$ Department of Physiology, Monash University, Clayton, VIC, Australia
}

Edited by:

Ishwar Parhar, Monash University, Malaysia

Reviewed by:

Charlotte A. Cornil, University of

Liege, Belgium

Gustavo M. Somoza, Instituto de

Investigaciones

Biotecnologicas-Instituto

Tecnologico de Chascomus

(IIB-INTECH), Argentina

*Correspondence:

Vance L. Trudeau, University

Research Chair in

Neuroendocrinology, Department of

Biology, Centre for Advanced

Research in Environmental

Genomics, University of Ottawa, 20

Marie Curie, Ottawa, ON K1N 6N5,

Canada

e-mail: trudeauv@uottawa.ca
Chemical communication via sex pheromones is critical for successful reproduction but the underlying neural mechanisms are not well-understood. The goldfish is a tractable model because sex pheromones have been well-characterized in this species. We used male goldfish forebrain explants in vitro and performed whole-cell current clamp recordings from single neurons in the ventral preoptic area (VPOA) to characterize their membrane properties and synaptic inputs from the olfactory bulbs (OB). Principle component and cluster analyses based on intrinsic membrane properties of VPOA neurons $(N=107)$ revealed five $(I-V)$ distinct cell groups. These cells displayed differences in their input resistance $\left(\mathrm{R}_{\text {input }}: I<I \mid<\mathrm{IV}<\mathrm{III}=\mathrm{V}\right)$, time constant $(\mathrm{TC}: \mathrm{I}=\mathrm{II}<\mathrm{IV}<\mathrm{III}=\mathrm{V}$ ), and threshold current ( $\left.\left.\right|_{\text {threshold }}: \mid>I I=I V>I I=V\right)$. Evidence from electrical stimulation of the OB and application of receptor antagonists suggests that VPOA neurons receive monosynaptic glutamatergic inputs via the medial olfactory tract, with connectivity varying among neuronal groups [I (24\%), II (40\%), III (0\%), IV (34\%), and V (2\%)].

\section{Keywords: ventral preoptic area, male goldfish, monosynaptic glutamatergic projections}

\section{INTRODUCTION}

Chemical communication plays a vital role in vertebrate reproduction. Biologically-active sex pheromones have evolved across the animal kingdom to convey reproductive information to conspecifics (Dulac and Torello, 2003). However, in most cases, the neural circuitry associated with the processing of sex pheromones is poorly understood. Chemical communication is especially important in animals like goldfish because they rely on external fertilization and often live in turbid waters. These fish have evolved sex pheromones to synchronize spawning between the sexes and thus ensure reproductive success. Further, the goldfish is an attractive model to study the neural substrates of chemical communication because it is one of the few vertebrates whose sex pheromones have been fully characterized (Stacey et al., 1989; Sorensen et al., 1991; Dulka, 1993).

Studies of male goldfish indicate that sex pheromones from females regulate male sexual behavior and milt production by inducing the release of luteinizing hormone (LH) from the male pituitary gland through stimulation of gonadotropin-releasing hormone $(\mathrm{GnRH})$ in the POA (Stacey, 1983; Kobayashi et al., 1986, 2002; Trudeau, 1997). The POA controls the release of LH (Peter et al., 1990; Chang et al., 2000; Trudeau et al., 2000a,b) via a signaling pathway involving dopamine (DA), which tonically inhibits both GnRH and LH release (Peter and Paulencu, 1980; Kah et al., 1987; Sloley et al., 1992; Popesku et al., 2011). Coupled to the GABAergic inputs this area receives from the ventral telencephali pars ventralis (Vv) (Martinoli et al., 1990; Trudeau et al., 2000b), the vPOA may be the site where DA suppression of GnRH is removed to allow increased GnRH levels to elicit LH release and subsequent spawning.

To characterize the neural pathways underlying the $\mathrm{OB}$ and POA networks, we have developed a novel in vitro explant preparation of the goldfish forebrain (Trudeau et al., 2000b). The adult goldfish brain is small and relatively unmyelinated making it attractive for patch clamp electrophysiology. In addition, the explant preserves the underlying neural circuitry yet allows for easy access to neurons on the ventral surface of the brain.

Here, we first describe the intrinsic membrane properties of neurons in the vPOA. Based on these properties, we suggest that $\mathrm{vPOA}$ neurons comprise five different subgroups. We then characterized the synaptic projections from the $\mathrm{OB}$ to the vPOA. In the goldfish and the closely related Crucian carp, the lateral olfactory tract (LOT) transmits food-related odors (Dulka, 1993; Hamdani et al., 2001a,b) while the medial olfactory tract (MOT) conveys exclusively pheromonal and social signals (Demski and Dulka, 1984; Sorensen et al., 1991; Hamdani et al., 2000). Here, we demonstrate that there are functional glutamatergic projections from the $\mathrm{OB}$ to the POA through the MOT. 


\section{MATERIALS AND METHODS EXPERIMENTAL ANIMALS}

This study was approved by the animal care committee of the University of Ottawa and carried out in accordance with the guidelines of Canadian Council on Animal Care. Common goldfish (Carassius auratus) weighing 15-40 g were purchased from a commercial supplier (Aleong's International Inc., Mississauga, $\mathrm{ON}$, Canada). Fish were acclimated to $18^{\circ} \mathrm{C}$, fed and maintained on a simulated photoperiod as previously reported (Trudeau et al., 1991). Only male goldfish were used throughout the study. During spawning season, sexually mature males were easily discernable by their distinctive tubercles and some readily expressed milt when their anogenital area was gently pressed. After the spawning season and during recrudescence, when tubercles are not always evident, sex was confirmed post-mortem by visual inspection of the testes.

Fish were anesthetized by immersion in $0.05 \%$ tricaine methanesulphonate (TMS) prior to dissection of the brain explant. Briefly, after severing the spinal cord, the skull was carefully opened with surgical scissors to expose the brain. The brain was dissected out from the skull cavity by cutting the optic nerves, and then removing the whole brain with olfactory bulbs still attached. The explant was attached to a Petri-dish ventral side up at the level of the spinal cord and cerebellum with cyanoacrylate glue, and placed in a bath with ice-cold artificial cerebrospinal fluid (ACSF) of the following composition [mM]: $127 \mathrm{NaCl}, 1.9$ $\mathrm{KCl}, 1.2 \mathrm{KH}_{2} \mathrm{PO}_{4}, 2.4 \mathrm{CaCl}_{2}, 1.3 \mathrm{MgCl}_{2}, 26 \mathrm{NaHCO}_{3}, 10 \mathrm{D}-$ glucose; gassed with carbogen $\left(95 \mathrm{O}_{2}, 5 \% \mathrm{CO}_{2}\right) ; \mathrm{pH}$ adjusted to 7.4 with $\mathrm{NaOH}$. The ACSF was modified from rats' ACSF (Spanswick et al., 1998) and it was similar to others (ACSF) in other fish such as Apteronotus leptorhynchus (Kotecha et al., 1997) and C. auratus (Wilkie et al., 2008). When magnesium-free solution was used, $\mathrm{MgCl}_{2}$ was omitted from the ACSF.

The meninges were removed with fine forceps to expose the ventral telencephalon and access the vPOA; then a transverse cut using a razor blade was made posterior to the hypothalamus to free the brain from the dish. The brain was then transferred carefully to a custom-built recording chamber perfused at room temperature with ACSF at a rate of $2-4 \mathrm{ml} / \mathrm{min}$. The brain explant was mounted with the ventral side up and then held between two custom-made nylon grids where it was allowed to recover for $1 \mathrm{~h}$ prior to recordings; all recordings were made in the $7 \mathrm{~h}$ following dissection. Neuroanatomical nomenclature in this study follows that of Anglade et al. (1993). Our vPOA corresponded to nucleus preopticus periventricularis as depicted in Plate 43 of the goldfish brain atlas (Peter and Gill, 1975).

\section{ELECTROPHYSIOLOGICAL RECORDINGS}

Electrophysiological recordings were made based on previous methods for rat spinal cord and hypothalamus (Spanswick et al., 1998). Whole-cell patch clamp recordings using a Multiclamp 700B amplifier (Molecular Devices) in current clamp mode, were obtained from vPOA neurons $(N=107)$ in the in vitro forebrain explants at room temperature $\left(\sim 18-20^{\circ} \mathrm{C}\right)$ from 120 fish. Patch pipettes (5-8 M $\Omega$ ) were fabricated from borosilicate filament glass (Sutter Instrument Co., Novata, CA, USA) using a horizontal pipette puller (P2000; Sutter Instrument Co., Novata,
CA, USA) and filled with intracellular solution of the following composition $[\mathrm{mM}]$ : $140 \mathrm{~K}$-gluconate, $10 \mathrm{KCl}, 1$ sucrose, 2 $\mathrm{Na}_{2} \mathrm{ATP}, 1$ EGTA-Na 4 plus 10 HEPES and $\mathrm{pH}$ adjusted to 7.4 with $\mathrm{KOH}$ modified from Spanswick et al. (1998).

Using the anterior commissure and optic chiasm as landmarks, patch electrodes were guided to the vPOA under visual control of a dissecting microscope. Seal formation was monitored on an oscilloscope. Once a gigaohm seal (typically $>5 \mathrm{G} \Omega$ ) was achieved, whole-cell access was made by gentle suction. Series resistance was $<25 \mathrm{M} \Omega$.

To measure synaptic connectivity, a bipolar stimulating electrode was inserted into one of the olfactory bulbs (OBs). Postsynaptic potentials (PSPs) in the vPOA were elicited by single pulse electrical stimulation (5-30 V, $0.2 \mathrm{~ms}$ pulse duration) of the ipsilateral OB via a stimulus isolation unit (Digitimer Ltd., model DS2). Data acquisition and experimental control was performed using PCLAMP 9.2 software (Molecular Devices). Data were lowpass filtered at $2 \mathrm{kHz}$ and acquired at $10 \mathrm{kHz}$ and later analyzed offline using CLAMPFIT 9.2 software (Molecular Devices).

\section{PHARMACOLOGICAL AGENTS}

To characterize the pharmacological properties of the connectivity from the $\mathrm{OB}$ to the $\mathrm{vPOA}$ neurons, we used 6-cyano-7-nitroquinoxaline-2, 3-dione (CNQX; Tocris), an $\alpha$-amino-3-hydroxy-5-methyl-4-isoxazolepropionic acid (AMPA/kainate) receptor antagonist; and D-2-amino-5-phosphonopentanoic acid (D-APV; Tocris), an N-Methyl-D-aspartic acid or N-Methyl-D-aspartate (NMDA) receptor antagonist. Drugs were made up as stock solutions, CNQX in DMSO (Sigma-Aldrich) and D-APV in distilled water, then, diluted in $\mathrm{Mg}^{2+}$ free ACSF. The final concentration of DMSO was always < $0.1 \%$. Typically, $\mathrm{Mg}^{2+}$ free ACSF and the drugs were applied sequentially for $10 \mathrm{~min}$ each to the recording chamber before any attempts at recordings to allow sufficient equilibration time.

\section{DATA ANALYSIS}

Intrinsic membrane properties of vPOA neurons were characterized by patch clamp electrophysiology to determine whether they constituted distinct populations. After achieving whole cell access, the resting membrane potential (RMP) which is the baseline potential in the absence of any current stimulus was measured in current clamp mode $(I=0 \mathrm{nA})$. In addition, properties related to spontaneous action potential production was measured (Figure 1A): Spike amplitude (SA) was measured from the shoulder of the rising phase ( $\sim$ threshold) to the peak; spike width $\left(S_{\text {width }}\right)$ was measured at the width of half-maximal from the peak to the afterhyperpolarization (AHP); AHP was determined from the threshold to the peak of the hyperpolarization following the action potential (note that only the fast component of the AHP was considered in this study); after-depolarization potential (ADP) was measured from the hyperpolarization peak to the ADP peak. For neurons that showed spontaneous activity, the coefficient of variation of the interspike interval (the interval between successive spikes) was calculated over a $90 \mathrm{~s}$ time window $\left(\mathrm{CV}_{\text {spikes }}=\mathrm{SD} /\right.$ mean $)$. Neurons were then stimulated with $1 \mathrm{~s}$ hyperpolarizing and depolarizing current steps (2-30 pA) from a holding potential of $-60 \mathrm{mV}$ to measure a number of other 


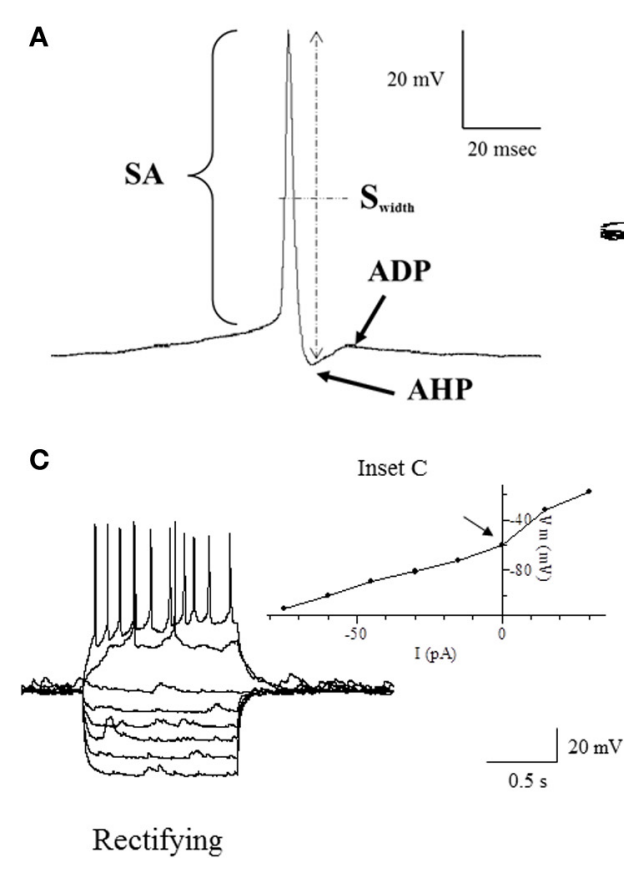

FIGURE 1 | Traces of some of the intrinsic membrane properties used in our statistical analyses. (A) Depicts the AHP (after hyperpolarization potential), APA (action potential amplitude), APD (action potential duration) and ADP (after depolarization potential). (B) Shows the RD (rebound depolarization) and RDS (rebound depolarization spikes). (C,D) demonstrate

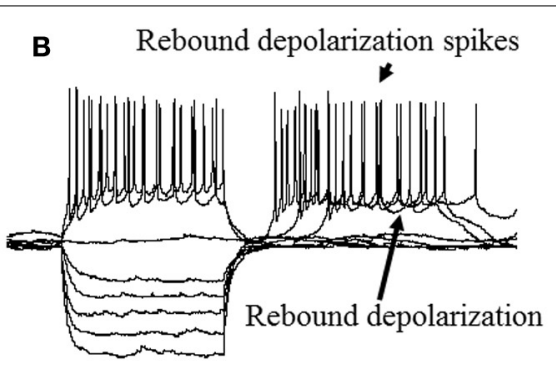

D

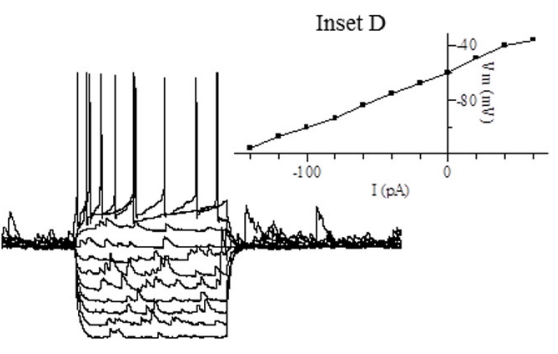

Non-rectifying

the current to voltage relationship (IV) where (C) is rectifying as shown by the arrow at the inflection point (Inset C) and (D) is non-rectifying (Inset D). APA was measured from the shoulder at threshold shown by the arrowhead. APD was the width of the AP measured from the shoulder at threshold shown by the arrowhead. See definitions in Materials and Methods section.

intrinsic membrane properties (Figures 1B-D): current threshold $\left(\mathrm{I}_{\text {threshold }}\right)$ is the minimum current required to elicit an action potential; spike threshold ( $S_{\text {threshold }}$ ) is the number of spikes elicited by the minimum current i.e., at $\mathrm{I}_{\text {threshold}}$; the presence or absence of a rebound depolarization (RD) after a hyperpolarizing current step; the presence or absence of rebound depolarization spikes (RDS), rebound spike frequency (RS) is the action potential frequency during the RD; the presence or absence of $\mathrm{H}$ current $\left(\mathrm{I}_{\mathrm{H}}\right)$ which is associated with non-selective cation channels; rectification (Rec) refers to a non-linearity in the current-voltage (IV) relationship (Siegelbaum and Koester, 2000) (compare insets in Figures 1C,D); the input resistance ( $\left.\mathrm{R}_{\text {input }}\right)$, which is the slope of the IV curve; membrane time constant (TC) is the time for the hyperpolarization response to reach two-thirds of its plateau value; soma membrane capacitance $\left(\mathrm{C}_{\text {soma }}\right)$ is calculated as TC/ $\mathrm{R}_{\text {input }}$ (Abbud and Smith, 1995).

A principle component analysis (PCA; SPSS Inc.; 2006, v.15) was used to reduce the set of intrinsic membrane properties to a number of independent uncorrelated variables. For this analysis, all properties that were characterized by their presence or absence, i.e., $\mathrm{RD}, \mathrm{RDS}, \mathrm{I}_{\mathrm{H}}$ and $\mathrm{Rec}$ were assigned binary values $(0,1)$. The PCA variables were then used to cluster (SPSS Inc.; 2006, v.15) the neurons into groups. An unsupervised cluster analysis was performed to classify neurons, similar to previous studies (Ward, 1963; Krimer et al., 2005; Sosulina et al., 2006; Andjelic et al., 2009). This method consisted of grouping individual neurons based on the Euclidean distance between their respective PCA loadings.
Postsynaptic potentials (PSP) data were characterized by the peak amplitude (the height of the evoked PSP measured from baseline to peak), the latency (the time between the OB stimulus and beginning of PSP rise), 10-90\% rise time (measured from the shoulder of the rise to the peak) and 90\%-10\% decay time (determined from $90 \%$ of the peak of the PSP to $10 \%$ above baseline) (Figure 2). To measure variability in the latency and rise time, the mean, standard deviation (SD) and coefficient of variation (CV); (SD/mean) was calculated over 4 stimulus trials in each cell.

All data generated by the PCA were tested for normality and homogeneity of variance, and either an analysis of variance (ANOVA) or a Kruskal-Wallis (KW) analysis was used for between group comparisons where appropriate (SPSS Inc.; 2006, v.15). Post-hoc analyses consisted of paired $t$-tests and Tukey's (SPSS Inc.; 2006, v.15). Unless otherwise stated, data are reported as mean \pm s.e.m.

\section{RESULTS \\ HETEROGENEITY OF INTRINSIC MEMBRANE PROPERTIES}

To characterize the population of vPOA neurons, a number of intrinsic membrane properties were quantified (see Materials and Methods). We used a Principle Component Analysis (PCA) to determine the set of properties that could best distinguish neuronal subgroups. The PCA revealed seven significant properties (loading factor) [RD (0.92), $\mathrm{R}_{\text {input }}(0.87)$, SA (0.77), $\mathrm{S}_{\text {threshold }}$ (0.80), RS (0.82), $\mathrm{I}_{\mathrm{H}}(0.78)$, and Rec (0.83)] (Table 1). A subsequent cluster analysis of these variables revealed five distinct neuronal subgroups (denoted I, II, III, IV, and V). In the following, we 


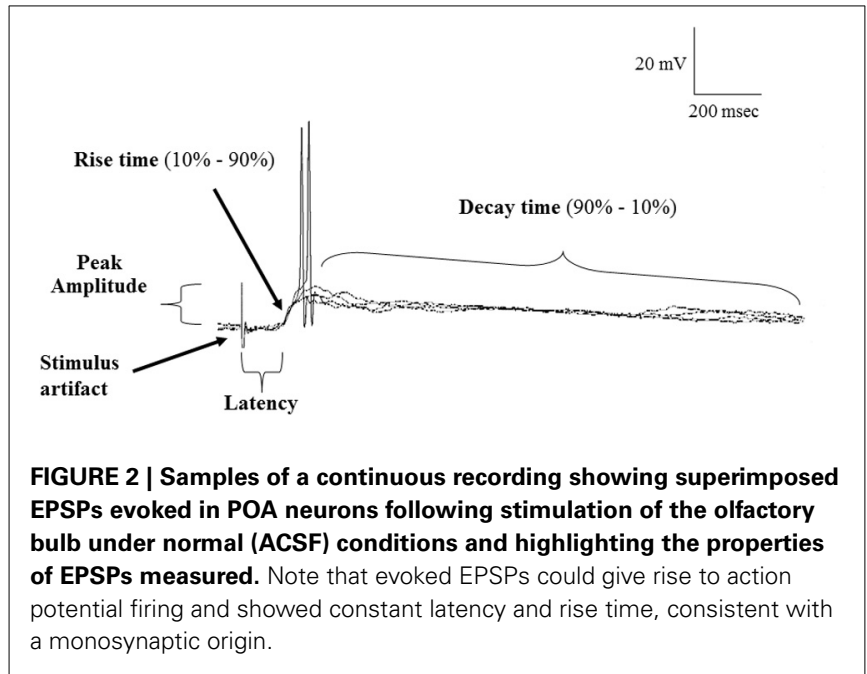

compare the membrane properties across the different subgroups (Table 2).

Since the data from our PCA failed the normality test $(P>$ $0.05)$, it was transformed to its square root equivalent; and statistical analyses performed. Neuronal subgroups were found to differ in their $\mathrm{R}_{\text {input }}\left[F_{(4,106)}=325.93, P=0.001\right]$, $\mathrm{TC}\left[F_{(4,106)}=\right.$ $13.63, P=0.001]$ and $\mathrm{I}_{\text {threshold }}\left[F_{(4,106)}=3.86, P=0.006\right]$ but not $\operatorname{ADP}\left[F_{(4,106)}=1.35, P=0.25\right]$. Tukey's post-hoc analyses showed that $\mathrm{R}_{\text {input }}$ was different in each neuronal cluster with $\mathrm{V}=\mathrm{III}>\mathrm{IV}>\mathrm{II}>\mathrm{I}$ (Figure 3A). Similarly, the TC of neurons in clusters III and $\mathrm{V}$ were higher than IV which in turn was higher than those in clusters I and II (Figure 3B). In addition, $\mathrm{I}_{\text {threshold }}$ for neurons in cluster I was greater than II which in turn was greater than for IV greater than III and V neurons (Figure 3C). Since the rectification ( $\mathrm{Rec}$ ) and RS were categorical variables, post-hoc comparisons were performed using KW analyses: rectification was not significant $\left[\chi_{(4)}^{2}=1.55 ; P=0.818\right]$ nor was RS $\left[\chi_{(4)}^{2}=10.28 ; P=0.036\right.$, Bonferroni correction, $P>0.005]$.

Overall, our analyses showed that only $\mathrm{R}_{\text {input }}, \mathrm{TC}$ and $\mathrm{I}_{\text {threshold }}$ were significantly different between groups $(P<0.05)$, while rectification and RS were not $(P>0.05)$. Together, the $\mathrm{R}_{\text {input }}$, TC and $\mathrm{C}_{\text {soma }}$ constitute the passive membrane properties of the cell. Note that the TC is directly proportional to the product of the $\mathrm{R}_{\text {input }}$ and $\mathrm{C}_{\text {soma }}\left[\mathrm{TC}=\mathrm{R}_{\text {input }}\right.$. $\left.\mathrm{C}_{\text {soma }}\right]$ (Molleman, 2003). The calculated $\mathrm{C}_{\text {soma }}$ (after its transformation to the reciprocal of its square root to normalize the data) was also statistically different between neuronal groups $\left[F_{(4,106)}=25.89, P=0.001\right]$, with Tukey's post-hoc indicating that I $>\mathrm{II}>\mathrm{IV}>\mathrm{III}=\mathrm{V}$ (Figure 3D). Since capacitance is proportional to membrane area (Hille, 2001), the differences we observe between neuronal groups can be at least partially explained by neuronal size.

\section{PROPERTIES OF POSTSYNAPTIC POTENTIALS: INPUTS FROM THE OLFACTORY BULB}

Given these putative subgroups of vPOA neurons, we next set out to determine their inputs from the olfactory bulb (OB). Of the $107 \mathrm{vPOA}$ cells tested, 50 received synaptic inputs from the
OB. The ratio of connected to unconnected neurons in each cluster was: I: $59 \%$ (12/23); II: 60\% (20/38); III: 0\% (0/4); IV: 53\% (17/36); and V: $19 \%(1 / 6)$.

The PSPs were reliably evoked with latencies of approximately $90 \mathrm{~ms}$. The small coefficients of variation (CV) of the latency $(1.5 \%)$ and rise-time $(2.2 \%)$ within cells are not consistent with a multi-synaptic pathway (for which latency is expected to be more variable). Given the consistency of the synaptic response, we suggest that these connections are monosynaptic (Spanswick et al., 1998). Since the distance from the OB to the POA is about $9 \mathrm{~mm}$, a latency of $100 \mathrm{~ms}$ suggests an estimated conduction velocity similar to the slowest conduction velocity $(\sim 0.1 \mathrm{~m} / \mathrm{s})$ reported in olfactory nerves of the tench at similar temperatures (Dubois-Dauphin et al., 1980).

\section{BIOCHEMICAL PROPERTIES OF THE POSTSYNAPTIC POTENTIALS OF vPOA}

To characterize the pharmacological properties of the PSP in vPOA $(N=13)$ neurons, goldfish brain explants were perfused sequentially with normal ACSF, $\mathrm{Mg}^{++}$-free ACSF (MFACSF), $20 \mu \mathrm{M}$ D-APV and $10 \mu \mathrm{M}$ CNQX before washing off both drugs with normal saline. The latency, peak amplitude rise and decay times of the evoked PSPs were then measured and compared under the different recording conditions. Figure 4 shows representative data from a vPOA neuron. The $\mathrm{Mg}^{2+}$ free ACSF increased the PSP compared to normal saline. The glutamate antagonist APV partially blocked the evoked response. The residual response was subsequently blocked completely by CNQX, indicating that the PSPs had a dual component and were mediated by glutamate acting on both NMDARs and AMPARs (Figure 4). Indeed, when AMPARs alone were blocked with CNQX (data not shown; $N=10$ ), no EPSPs were evoked suggesting that activation of NMDARs requires preceding depolarization via AMPARs to overcome voltage-dependent $\mathrm{Mg}^{2+}$ block.

A statistical analysis on data obtained from POA neurons $(N=$ 13) did not find significant differences $(P>0.05)$ in their PSP latencies and rise times between the different perfusion media, but their decay times differed significantly between MFACSF vs. ACSF $\left[F_{(1,12)}=16.11, P=0.002\right]$ and MFACSF vs. APV $\left[F_{(1,12)}=16.59, P=0.002\right]$. Post-hoc analysis indicated that POA neurons in MFACSF had a longer decay time than in either $\operatorname{ACSF}\left[t_{(13)}=3.76, p=0.002\right]$ or APV $\left[t_{(13)}=4.07, p=0.002\right]$ (Figure 5). These data show that the evoked PSPs had a biphasic response, with APV partially blocking the slower and longer lasting NMDAR component, revealing a faster and shorter lasting AMPAR component that was completely blocked by CNQX.

\section{SECTIONING THE LATERAL OLFACTORY TRACT WHILE RECORDING FROM THE vPOA}

To determine if the OB to vPOA projection is mediated through the MOT, we sectioned the LOT $(N=3)$ while leaving the medial tract intact. We found that PSPs evoked in vPOA neurons by OB stimulation did not differ from those evoked under control conditions for latency, rise time, peak amplitude and decay times (KW analysis; $P>0.05)$. Cutting the MOT $(N=10)$ while leaving the LOT intact did not elicit any response consistent with studies which have shown that the MOT innervates targets in area 
Table 1 | The rotated component matrix of variables used in our principle component analysis.

\begin{tabular}{|c|c|c|c|c|c|c|c|}
\hline Property/Loaded factors & 1 & 2 & 3 & 4 & 5 & 6 & 7 \\
\hline TC (msec) & 0.224 & 0.769 & 0.210 & -0.065 & 0.120 & -0.160 & 0.228 \\
\hline $\mathrm{AHP}(\mathrm{mV})$ & -0.320 & 0.152 & 0.664 & -0.081 & 0.000 & -0.085 & -0.240 \\
\hline $\mathrm{SA}(\mathrm{mV})$ & 0.209 & 0.003 & 0.770 & -0.104 & 0.033 & -0.261 & 0.159 \\
\hline $\mathrm{S}_{\text {width }}(\mathrm{ms})$ & -0.061 & -0.043 & -0.784 & -0.340 & 0.043 & -0.189 & -0.092 \\
\hline CV & -0.038 & 0.285 & -0.172 & 0.218 & -0.720 & -0.086 & -0.225 \\
\hline RS & 0.171 & 0.086 & -0.079 & 0.056 & 0.782 & -0.018 & -0.126 \\
\hline $\mathrm{ADP}(\mathrm{mV})$ & 0.397 & -0.397 & 0.223 & -0.173 & -0.409 & -0.051 & -0.148 \\
\hline$I_{H}$ & 0.041 & -0.184 & -0.058 & -0.053 & -0.094 & 0.783 & 0.305 \\
\hline
\end{tabular}

Loaded factors in bold show measurements that were subsequently used for our cluster analysis. See definitions in Materials and Methods section and Figure 1. Extraction Method: Principal Component Analysis. Rotation Method: Varimax with Kaiser Normalization. Rotation converged in 8 iterations.

Table 2 | Intrinsic membrane properties of POA neurons measured in ACSF.

\begin{tabular}{|c|c|c|c|c|c|}
\hline Property/Clusters & $\begin{array}{c}I \\
(N=23)\end{array}$ & $\begin{array}{c}\text { II } \\
(N=38)\end{array}$ & $\begin{array}{c}\text { III } \\
(N=4)\end{array}$ & $\begin{array}{c}\text { IV } \\
(N=36)\end{array}$ & $\begin{array}{c}V \\
(N=6)\end{array}$ \\
\hline $\mathrm{RMP}(\mathrm{mV})$ & $-56.5 \pm 2.2$ & $-58.2 \pm 1.4$ & $-57.1 \pm 4.5$ & $-56 \pm 1.4$ & $-54.3 \pm 2.1$ \\
\hline $\mathrm{R}_{\text {input }}(\mathrm{G} \Omega)$ & $0.42 \pm 0.04$ & $1.0 \pm 0.03$ & $3.7 \pm 0.15$ & $2.0 \pm 0.07$ & $5.9 \pm 0.04$ \\
\hline $\mathrm{C}_{\text {soma }}(\mathrm{pF})$ & $144.3 \pm 24$ & $45.8 \pm 2.8$ & $24.9 \pm 3.7$ & $34.3 \pm 3.4$ & $19.2 \pm 2.8$ \\
\hline $\mathrm{AHP}(\mathrm{mV})$ & $12.2 \pm 1.3$ & $10.2 \pm 0.8$ & $13.7 \pm 5.8$ & $11.0 \pm 1.0$ & $15.4 \pm 3.7$ \\
\hline$I_{\text {threshold }}(\mathrm{pA})$ & $13.0 \pm 2.0$ & $8.2 \pm 1.2$ & $3.9 \pm 0.8$ & $6.0 \pm 0.7$ & $3.3 \pm 0.8$ \\
\hline$S_{\text {threshold }}(\mathrm{Hz})$ & $3.3 \pm 0.6$ & $2.4 \pm 0.3$ & $2 \pm 0.4$ & $3.5 \pm 0.4$ & $5.3 \pm 1.0$ \\
\hline CV & $1.1 \pm 0.1$ & $1.1 \pm 0.1$ & $1.0 \pm 0.1$ & $1.1 \pm 0.1$ & $2.3 \pm 0.6$ \\
\hline $\mathrm{ADP}(\mathrm{mV})$ & $1.4 \pm 0.4$ & $1.6 \pm 0.4$ & - & $0.6 \pm 0.2$ & $0.12 \pm 0.0$ \\
\hline
\end{tabular}

RMP (resting membrane potential); TC (membrane time constant); $R_{\text {input }}$ (input resistance); $C_{m}$ (membrane capacitance); AHP (after hyperpolarization potential); APA (action potential amplitude); TI (action potential threshold current); ST (number of spikes at threshold current); APD (action potential duration); CV (coefficient of variation); ADP (after depolarization potential). Not shown are variables for rectifying and RS. See definitions in Materials and Methods section and Figure 1.

dorsalis and area ventralis while the LOT projects only to area dorsalis (Levine and Dethier, 1985). Furthermore, pharmacological manipulations influenced the recorded EPSPs in similar ways for both cut and intact LOTs for latency, rise time, peak amplitude and decay times (KW analysis; $P>0.05$ ). Sectioning both the medial and LOTs abolished the PSPs completely. This confirms that the pathway we describe from $\mathrm{OB}$ to $\mathrm{POA}$ is via the MOT.

\section{DISCUSSION}

Female sex pheromones regulate reproduction in male goldfish through the olfactory system (Partridge et al., 1976; Sorensen et al., 1991; Dulka, 1993; Stacey et al., 2003; Chung-Davidson et al., 2008). Previous anatomical studies have shown direct neuronal pathways from the $\mathrm{OB}$ to POA in the teleost brain (Forlano and Bass, 2011). With whole-cell patch clamp recordings, we show for the first time that these connections are functional and glutamatergic. In addition, we show that these synapses involve both $\mathrm{N}$-methyl-D-aspartate (NMDAR) and $\alpha$-amino-3-hydroxy-5methyl-4-isoxazolepropionic acid receptors (AMPAR). We also provide evidence, with a thorough characterization of electrophysiological properties, that neurons of the vPOA comprise several subgroups.

The POA is an important hypophysiotropic center that regulates reproduction in vertebrates. Electrical stimulation of this area has been shown to elicit sperm release (Demski, 1983; Dulka and Demski, 1986; Dulka, 1993; Dominguez, 2009); sexual calling (Schmidt, 1968); nest-building and courtship (Demski and Knigge, 1971) in several vertebrate models. Conversely, lesioning the POA impairs reproduction in male goldfish thereby underscoring the importance of this neural system (Hart et al., 


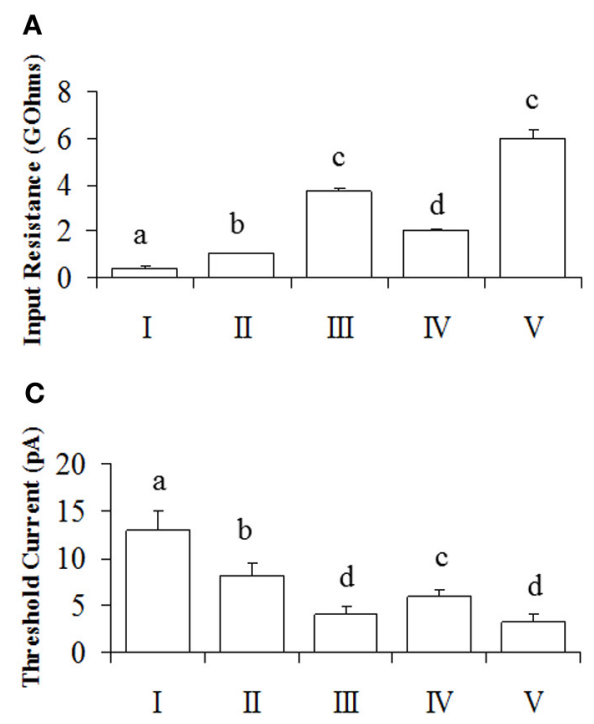

FIGURE 3 | Intrinsic membrane properties of POA neurons. Neurons were made up of connected ( $N=50)$ and unconnected $(N=57)$ neurons to the OB. (A) The input resistance showing group differences. (B) The time constant, indicating differences between groups. (C) The threshold current

\section{B}

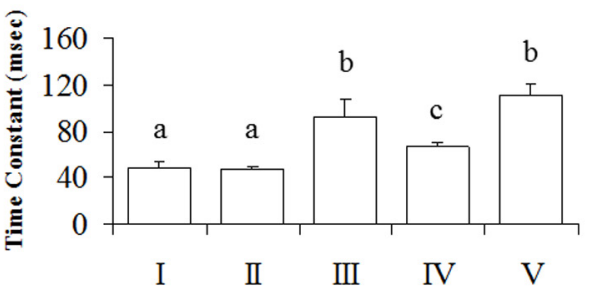

D

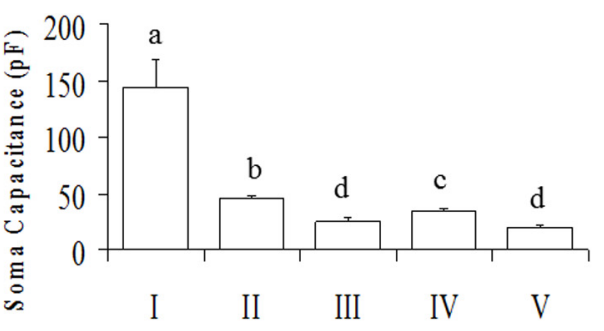

differences between groups. Results are presented as mean \pm s.e.m. for convenience. Letters represent groups that differed significantly $(P<0.005)$ from each other with Bonferroni corrections. (D) Soma capacitances of the different neuronal groups.

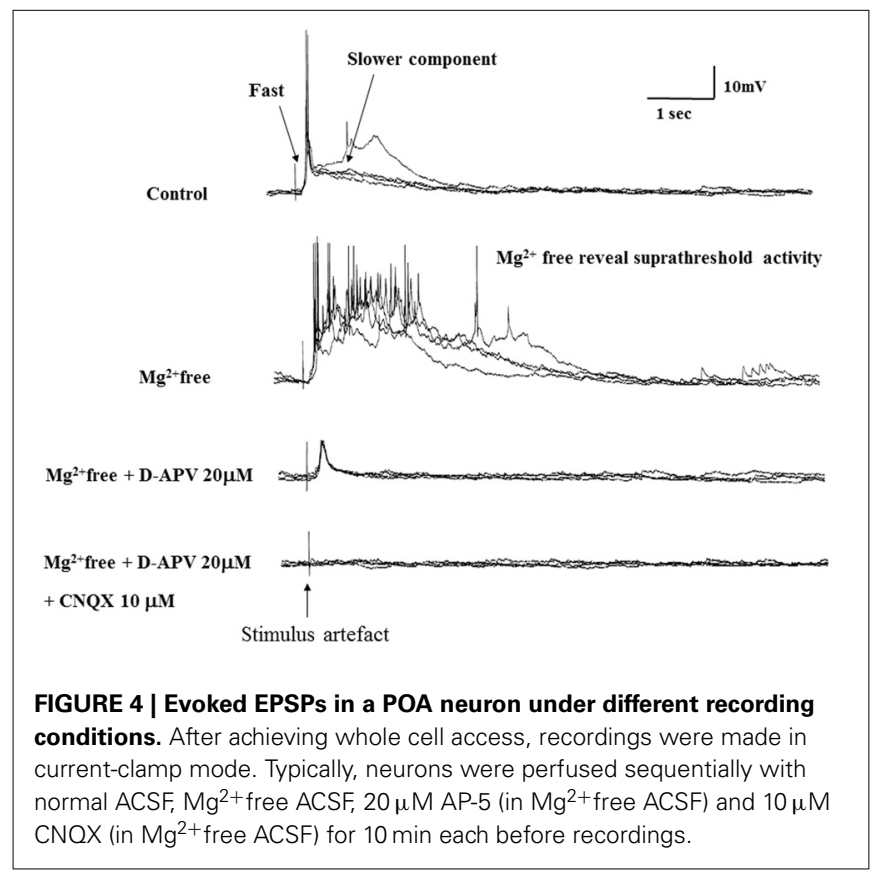

1973; Kyle and Peter, 1982; Kyle et al., 1982; Koyama et al., 1984; Sorensen et al., 1991; Dulka, 1993).

\section{HETEROGENEITY OF NEURONAL ELECTRICAL PROPERTIES}

We recorded from neurons in the vPOA while stimulating the OB. Our analysis revealed five subgroups of vPOA neurons, each with distinct intrinsic membrane properties and variable connectivity to the OB. Indeed, the POA has been shown to contain a plethora of cells immunoreactive to substance P (Sharma et al.,

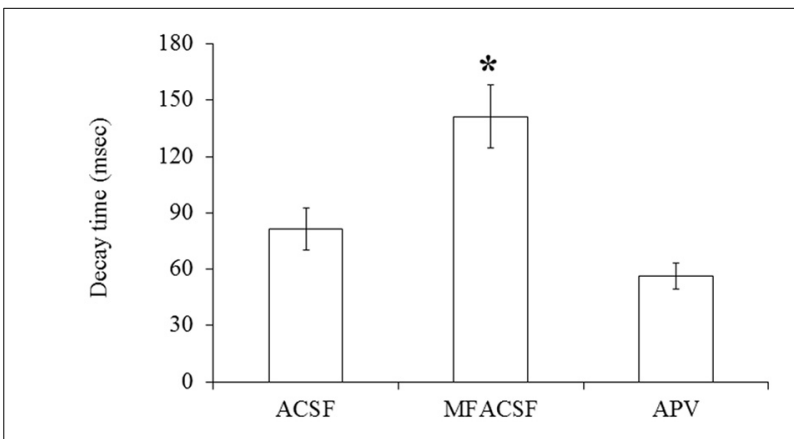

FIGURE 5 | The PSP decay time of POA neurons connected to the OB under the different perfusions (normal ACSF, $\mathrm{Mg}^{2+}$ free ACSF (MFACSF) and APV). Error bars denote s.e.m. Asterisks $\left({ }^{*}\right)$ statistical significance $(P<0.05)$ between perfusions.

1989), GnRH (Peter et al., 1990, 2003; Parhar et al., 2001), $\gamma$ aminobutyric acid (GABA) (Martinoli et al., 1990), glutamate (Anglade et al., 1993), somatostatin (Canosa et al., 2004), CRF (Olivereau et al., 1984), secretoneurin (Canosa et al., 2011) vasotocin (Parhar et al., 2001) and tyrosine hydroxylase (Hornby et al., 1987). Thus, this heterogeneity in electrophysiological profiles may reflect functionally diverse classes of vPOA neurons. Further work is required to determine if these electrophysiological "signatures" correspond to chemical phenotypes, exhibiting differential projections and functional roles.

\section{PROPERTIES OF POSTSYNAPTIC POTENTIALS: INPUTS FROM OLFACTORY BULB}

Electrical stimulation of the OB evoked PSPs in vPOA neurons. These PSPs gave rise to action potentials at the peak of their 
responses in some cases. The evoked excitatory PSPs (EPSPs) had consistent and constant latencies and rise times with small coefficient of variation suggesting they arise through monosynaptic inputs from the OB (Spanswick et al., 1998). The conduction velocities of the inputs from the $\mathrm{OB}$ to the POA were similar to those found previously in other systems (Gasser, 1956; Potapov and Gusel'nikova, 1976b). The relatively slow conduction is consistent with propagation through unmyelinated olfactory fibers (Westerman and Wilson, 1968; Potapov and Gusel'nikova, 1976a; Farbman, 1992). The conduction velocity of the inputs from the OB to the vPOA was estimated to be $0.1 \mathrm{~m} / \mathrm{s}$, which was similar to the pike (Gasser, 1956) and slower, by four times, than that reported by Kandel (1964) in the goldfish for the larger POA magnocellular neurons projecting to the neural lobe of the pituitary gland when stimulated antidromically.

\section{BIOCHEMICAL PROPERTIES OF THE SYNAPTIC CONNECTIONS}

Anatomical connections between the OB and vPOA have been established previously through tract-tracings (Levine and Dethier, 1985; Anglade et al., 1993), but their functional nature remains unclear. To investigate the possible role of glutamate in chemical communication, we perfused the goldfish brain explant sequentially with ACSF, APV, and CNQX in $\mathrm{Mg}^{2+}$ free ACSF while stimulating the $\mathrm{OB}$ to measure the latency, amplitude, rise time, decay time and duration of the evoked potentials in the vPOA (Figure 4). $\mathrm{Mg}^{2+}$ free ACSF enhanced the evoked EPSPs compared to normal ACSF. The NMDAR antagonist APV partially blocked the EPSPs leaving a fast acting and short lasting component that was subsequently completely blocked by CNQX, suggesting that the evoked PSP was mediated by glutamate acting on NMDARs and AMPARs, respectively. Receptors for AMPA may therefore be required to depolarize the cells (from their resting state) sufficiently to relieve the $\mathrm{Mg}^{2+}$ blockage of NMDARs (Gotz et al., 1997; Spanswick et al., 1998). Bath application of drugs allows for the possibility that the observed effects are indirect and involve peripheral pathways. However, given that the latency and rising phase of the evoked response is very consistent and remains so during drug application, the effects are likely direct.

The complete blockage of the evoked PSPs by the glutamatergic antagonists suggests that glutamate plays an important role in mediating chemical communication between the $\mathrm{OB}$ and vPOA. Since the POA is important for the regulation of reproductive behaviors, it may receive pheromonal cues from the OB to integrate milt release and spawning in male goldfish (Kyle and Peter, 1982; Kyle et al., 1982). The use of glutamate signaling through NMDA receptors may therefore be a mechanism to induce the sustained neuronal firing required to trigger an LH surge when sex pheromones are detected. To our knowledge, this is the first pharmacological characterization of second order neurons in the teleost olfactory system linked to reproduction.

A monosynaptic glutamatergic connection from the $\mathrm{OB}$ to the vPOA complements and extends our understanding of the neural circuitry involved in the control of goldfish reproduction. Previously, Trudeau et al. (2000b) demonstrated the existence of monosynaptic GABAergic projections from the $\mathrm{Vv}$ to the
vPOA. Indeed, GABA plays a central role in male goldfish reproduction by suppressing the DAergic inhibition of $\mathrm{LH}$ release (Trudeau et al., 1993). This suggests that there are interactions between diverse sets of neurotransmitters and neurohormones that regulate reproduction in male goldfish. The $\mathrm{Vv}$ may therefore modulate the glutamatergic inputs from the OB to the vPOA to regulate some aspects of reproductive behavior or hormone release.

\section{ROLE OF GLUTAMATE IN GOLDFISH REPRODUCTION}

Previous studies have shown that intraperitoneal injections of male goldfish with either monosodium glutamate (MSG) (Sloley et al., 1992) or NMDA (Trudeau et al., 2000b) or AMPA (Trudeau et al., 2000b; Popesku et al., 2011) rapidly induces LH release. Furthermore, in rainbow trout it has been shown that the $\mathrm{LH}$ response to NMDA is blocked by APV or a GnRH receptor antagonist, indicating that glutamate modulates $\mathrm{LH}$ release through stimulation of GnRH (Flett et al., 1994), similar to the situation in mammalian models (Kocsis et al., 2003). Moreover, Peter et al. (1980) has shown that MSG injections in goldfish causes cellular degeneration in the POA, demonstrating excitotoxic actions of glutamate on POA neurons. Additionally, in rats it has been shown that glutamate injections in the POA or electrical stimulation of the POA decreases the latency between intromissions thereby increasing ejaculation frequency (Dominguez, 2009). Glutamate in the POA therefore plays an important role in vertebrate reproduction.

\section{SECTIONING THE LATERAL OLFACTORY TRACT}

We employed olfactory tract sectioning to determine if the glutamatergic projection to the vPOA was via the MOT or the LOT. The EPSPs recorded in vPOA cells in explants with a transected LOT had the same amplitude and duration as those with the LOT intact. These EPSPs were modulated by APV and CNQX in the same way as in intact preparations. In other experiments, sectioning the MOT while leaving the LOT intact did not elicit PSPs in vPOA neurons indicating that the $\mathrm{OB}$ to $\mathrm{vPOA}$ projection we have studied is via the MOT and not the LOT. This supports previous studies indicating unequivocally that sex pheromones signals in goldfish are mediated exclusively by the MOT indeed tract tracing studies have shown that while the MOT projects to area dorsalis and area ventralis of the telencephalon the LOT only innervates targets in the area dorsalis (Levine and Dethier, 1985; Sorensen et al., 1991).

\section{CONCLUSION}

We describe an electrophysiological basis for classifying neurons of the vPOA. Further, we provide evidence that the synaptic connections from the $\mathrm{OB}$ to the vPOA are monosynaptic and glutamatergic. These connections from the OB to vPOA may play a role in facilitating spermiation and steroidogenesis (Peter and Paulencu, 1980; Peter et al., 1980; Kyle and Peter, 1982). While speculative at this point, the olfactory glutamatergic projections we identified may represent pathways that integrate pheromonal signals from females that stimulate reproductive hormone release and male sexual behavior in the spawning period. 


\section{AUTHOR CONTRIBUTIONS}

Wudu E. Lado, Vance L. Trudeau and David C. Spanswick designed the experiment. Wudu E. Lado and David C. Spanswick performed the experiment. Wudu E. Lado, John E. Lewis and Vance L. Trudeau analyzed the results and wrote the paper.

\section{ACKNOWLEDGMENTS}

We thank Dr. Andrew Whyment for invaluable advice and Bill Fletcher for technical assistance during the preparation of this manuscript. We acknowledge with appreciation Dr. Leo Renaud for his early support and encouragement to pursue this study. Funding from the University of Ottawa, NSERC to John E. Lewis and Vance L. Trudeau and OGS to Wudu E. Lado is gratefully acknowledged.

\section{REFERENCES}

Abbud, R., and Smith, M. S. (1995). Do GnRH neurons express the gene for the NMDA receptor? Brain Res. 690, 117-120. doi: 10.1016/0006-8993(95)00610-3

Andjelic, S., Gallopin, T., Cauli, B., Hill, E. L., Roux, L., Badr, S., et al. (2009). Glutamatergic nonpyramidal neurons from neocortical layer VI and their comparison with pyramidal and spiny stellate neurons. J. Neurophysiol. 101, 641-654. doi: 10.1152/jn.91094.2008

Anglade, I., Zandbergen, T., and Kah, O. (1993). Origins of the pituitary innervation in the goldfish. Cell Tissue Res. 273, 345-355. doi: 10.1007/BF00312837

Canosa, L. F., Cerda-Reverter, J. M., and Peter, R. E. (2004). Brain mapping of three somatostatin encoding genes in the goldfish. J. Comp. Neurol. 474, 43-57. doi: $10.1002 /$ cne.20097

Canosa, L. F., Lopez, G. C., Scharrig, E., Lesaux-Farmer, K., Somoza, G. M., Kah, O., et al. (2011). Forebrain mapping of secretoneurinâ€ like immunoreactivity and its colocalization with isotocin in the preoptic nucleus and pituitary gland of goldfish. J. Comp. Neurol. 519, 3748-3765. doi: 10.1002/cne.22688

Chang, J. P., Johnson, J. D., Van Goor, F., Wong, C. J., Yunker, W. K., Uretsky, A. D., et al. (2000). Signal transduction mechanisms mediating secretion in goldfish gonadotropes and somatotropes. Biochem. Cell Biol. 78, 139-153. doi: 10.1139/o00-011

Chung-Davidson, Y. W., Rees, C. B., Bryan, M. B., and Li, W. (2008). Neurogenic and neuroendocrine effects of goldfish pheromones. J. Neurosci. 28, 14492-14499. doi: 10.1523/JNEUROSCI.3589-08.2008

Demski, L. S. (1983). Behavioural Effects of Electrical Stimulation of the Brain. Ann Arbor, MI: University of Michigan Press.

Demski, L. S., and Dulka, J. G. (1984). Functional-anatomical studies on sperm release evoked by electrical stimulation of the olfactory tract in goldfish. Brain Res. 291, 241-247. doi: 10.1016/0006-8993(84)91256-3

Demski, L. S., and Knigge, K. M. (1971). The telencephalon and hypothalamus of the bluegill (Lepomis macrochirus): evoked feeding, aggressive and reproductive behavior with representative frontal sections. J. Comp. Neurol. 143, 1-16. doi: $10.1002 / \mathrm{cne} .901430102$

Dominguez, J. M. (2009). A role for preoptic glutamate in the regulation of male reproductive behavior. Neuroscientist 15, 11. doi: 10.1177/1073858408322679

Dubois-Dauphin, M., Dã Ving, K. B., and Holley, A. (1980). Topographical relation between the olfactory bulb and the olfactory tract in tench (Tinca tinca $\mathrm{L}$ ). Chem. Senses 5, 159-169. doi: 10.1093/chemse/5.2.159

Dulac, C., and Torello, A. T. (2003). Molecular detection of pheromone signals in mammals: from genes to behaviour. Nat. Rev. Neurosci. 4, 551-562. doi: $10.1038 / \mathrm{nrn} 1140$

Dulka, J. G. (1993). Sex pheromone systems in goldfish: comparisons to vomeronasal systems in tetrapods. Brain Behav. Evol. 42, 265-280. doi: $10.1159 / 000114166$

Dulka, J. G., and Demski, L. S. (1986). Sperm duct contractions mediate centrally evoked sperm release in goldfish. J. Exp. Zool. 237, 271-279. doi: $10.1002 /$ jez. 1402370213

Farbman, A. I. (1992). Cell Biology of Olfaction. New York, NY: Cambridge University Press.

Flett, P. A., Van Der Kraak, G., and Leatherland, J. F. (1994). Effects of excitatory amino acids on in vivo and in vitro gonadotropin and growth hormone secretion in testosterone-primed immature rainbow trout, Oncorhynchus mykiss. J. Exp. Zool. 268, 390-399. doi: 10.1002/jez.1402680508
Forlano, P. M., and Bass, A. H. (2011). Neural and hormonal mechanisms of reproductive-related arousal in fishes. Horm. Behav. 59, 616-629. doi: 10.1016/j.yhbeh.2010.10.006

Gasser, H. S. (1956). Olfactory nerve fibers. J. Gen. Physiol. 39, 473-496. doi: 10.1085/jgp.39.4.473

Gotz, T., Kraushaar, U., Geiger, J., Lubke, J., Berger, T., and Jonas, P. (1997). Functional properties of AMPA and NMDA receptors expressed in identified types of basal ganglia neurons. J. Neurosci. 17, 204-215.

Hamdani, E. H., Alexander, G., and Doving, K. B. (2001a). Projection of sensory neurons with microvilli to the lateral olfactory tract indicates their participation in feeding behaviour in crucian carp. Chem. Senses 26, 1139-1144. doi: 10.1093/chemse/26.9.1139

Hamdani, E. H., Kasumyan, A., and Doving, K. B. (2001b). Is feeding behaviour in crucian carp mediated by the lateral olfactory tract? Chem. Senses 26, 1133-1138. doi: 10.1093/chemse/26.9.1133

Hamdani, E. H., Stabell, O. B., Alexander, G., and Doving, K. B. (2000). Alarm reaction in the crucian carp is mediated by the medial bundle of the medial olfactory tract. Chem. Senses 25, 103-109. doi: 10.1093/chemse/25.1.103

Hart, B. L., Haugen, C. M., and Peterson, D. M. (1973). Effects of medial preoptic-anterior hypothalamic lesions on mating behavior of male cats. Brain Res. 54, 177-191. doi: 10.1016/0006-8993(73) 90043-7

Hille, B. (2001). Ion Channels of Excitable Membranes. Sunderland, MA: Sinauer.

Hornby, P. J., Piekut, D. T., and Demski, L. S. (1987). Localization of immunoreactive tyrosine hydroxylase in the goldfish brain. J. Comp. Neurol. 261, 1-14. doi: 10.1002/cne. 902610102

Kah, O., Dulka, J. G., Dubourg, P., Thibault, J., and Peter, R. E. (1987). Neuroanatomical substrate for the inhibition of gonadotrophin secretion in goldfish: existence of a dopaminergic preoptico-hypophyseal pathway. Neuroendocrinology 45, 451-458. doi: 10.1159/000124774

Kandel, E. R. (1964). Electrical properties of hypothalamic neuroendocrine cells. J. Gen. Physiol. 47, 691-717. doi: 10.1085/jgp.47.4.691

Kobayashi, M., Aida, K., and Hanyu, I. (1986). Pheromone from ovulatory female goldfish induces gonadotropin surge in males. Gen. Comp. Endocrinol. 63, 451-455. doi: 10.1016/0016-6480(86)90145-0

Kobayashi, M., Sorensen, P. W., and Stacey, N. E. (2002). Hormonal and pheromonal control of spawning behavior in the goldfish. Fish Physiol. Biochem. 26, 71-84. doi: 10.1023/A:1023375931734

Kocsis, K., Kiss, J., Csaki, A., and Halasz, B. (2003). Location of putative glutamatergic neurons projecting to the medial preoptic area of the rat hypothalamus. Brain Res. Bull. 61, 459-468. doi: 10.1016/S0361-9230(03)00180-1

Kotecha, S., Eley, D., and Turner, R. (1997). Tissue printed cells from teleost electrosensory and cerebellar structures. J. Comp. Neurol. 386, 277-292.

Koyama, Y., Satou, M., Oka, Y., and Ueda, K. (1984). Involvement of the telencephalic hemispheres and the preoptic area in sexual behavior of the male goldfish, Carassius auratus: a brain-lesion study. Behav. Neural Biol. 40, 70-86. doi: 10.1016/S0163-1047(84)90182-1

Krimer, L. S., Zaitsev, A. V., Czanner, G., Kröner, S., González-Burgos, G., Povysheva, N. V., et al. (2005). Cluster analysis-based physiological classification and morphological properties of inhibitory neurons in layers $2-$ 3 of monkey dorsolateral prefrontal cortex. J. Neurophysiol. 94, 3009. doi: 10.1152/jn.00156.2005

Kyle, A. L., and Peter, R. E. (1982). Effects of forebrain lesions on spawning behaviour in the male goldfish. Physiol. Behav. 28, 1103-1109. doi: 10.1016/0031-9384(82)90183-4

Kyle, A. L., Stacey, N. E., and Peter, R. E. (1982). Ventral telencephalic lesions: effects on bisexual behavior, activity, and olfaction in the male goldfish. Behav. Neural Biol. 36, 229-241. doi: 10.1016/S0163-1047(82)90855-X

Levine, R. L., and Dethier, S. (1985). The connections between the olfactory bulb and the brain in the goldfish. J. Comp. Neurol. 237, 427-444. doi: 10.1002/cne. 902370402

Martinoli, M. G., Dubourg, P., Geffard, M., Calas, A., and Kah, O. (1990). Distribution of GABA-immunoreactive neurons in the forebrain of the goldfish, Carassius auratus. Cell Tissue Res. 260, 77-84. doi: 10.1007/BF00297492

Molleman, A. (2003). Patch Clamping: An Introductory Guide to Patch Clamp Electrophysiology. Chichester: Wiley Online Library.

Olivereau, M., Ollevier, F., Vandesande, F., and Verdonck, W. (1984). Immunocytochemical identification of CRF-like and SRIF-like peptides in the brain and the pituitary of cyprinid fish. Cell Tissue Res. 237, 379-382. doi: $10.1007 / \mathrm{BF} 00217162$ 
Parhar, I. S., Tosaki, H., Sakuma, Y., and Kobayashi, M. (2001). Sex differences in the brain of goldfish: gonadotropin-releasing hormone and vasotocinergic neurons. Neuroscience 104, 1099-1110. doi: 10.1016/S0306-4522(01) 00153-1

Partridge, B. L., Liley, N. R., and Stacey, N. E. (1976). The role of pheromones in the sexual behaviour of the goldfish. Anim. Behav. 24, 291-299. doi: 10.1016/S00033472(76)80037-1

Peter, R. E., and Gill, V. E. (1975). A stereotaxic atlas and technique for forebrain nuclei of the goldfish, Carassius auratus. J. Comp. Neurol. 159, 69-101. doi: 10.1002/cne.901590106

Peter, R. E., Kah, O., Paulencu, C. R., Cook, H., and Kyle, A. L. (1980). Brain lesions and short-term endocrine effects of monosodium L-glutamate in goldfish, Carassius auratus. Cell Tissue Res. 212, 429-442. doi: 10.1007/BF00236508

Peter, R. E., and Paulencu, C. R. (1980). Involvement of the preoptic region in gonadotropin release-inhibition in goldfish, Carassius auratus. Neuroendocrinology 31, 133-141. doi: 10.1159/000123064

Peter, R. E., Prasada Rao, P. D., Baby, S. M., Illing, N., and Millar, R. P. (2003). Differential brain distribution of gonadotropin-releasing hormone receptors in the goldfish. Gen. Comp. Endocrinol. 132, 399-408. doi: 10.1016/S00166480(03)00084-4

Peter, R. E., Yu, K. L., Marchant, T. A., and Rosenblum, P. M. (1990). Direct neural regulation of the teleost adenohypophysis. J. Exp. Zool. S4, 84-89. doi: 10.1002/jez.1402560415

Popesku, J. T., Mennigen, J. A., Chang, J. P., and Trudeau, V. L. (2011). Dopamine D1 receptor blockage potentiates AMPA-stimulated luteinising hormone release in the goldfish. J. Neuroendocrinol. 23, 302-309. doi: 10.1111/j.13652826.2011.02114.x

Potapov, A. A., and Gusel'nikova, A. A. (1976a). [Electrotonic interaction of secondary neurons of the carp olfactory bulb]. Neirofiziologiia 8, 490-496.

Potapov, A. A., and Gusel'nikova, K. G. (1976b). Electrotonic interaction between secondary neurons of the carp olfactory bulb. Neurophysiology 8, 375-380. doi: 10.1007/BF01063598

Schmidt, R. S. (1968). Preoptic activation of frog mating behavior. Behaviour 30, 239-257.

Sharma, S. C., Berthoud, V. M., and Breckwoldt, R. (1989). Distribution of substance P-like immunoreactivity in the goldfish brain. J. Comp. Neurol. 279, 104-116. doi: 10.1002/cne.902790109

Siegelbaum, S. A., and Koester, J. (2000). "Ion channels," in Principles of Neural Science, eds E. R. Kandel, J. H. Schwartz, and M. T. Jessel (New York, NY: McGraw Hill), 105-124.

Sloley, B. D., Kah, O., Trudeau, V. L., Dulka, J. G., and Peter, R. E. (1992). Amino acid neurotransmitters and dopamine in brain and pituitary of the goldfish: involvement in the regulation of gonadotropin secretion. J. Neurochem. 58, 2254-2262. doi: 10.1111/j.1471-4159.1992.tb10971.x

Sorensen, P. W., Hara, T. J., and Stacey, N. E. (1991). Sex pheromones selectively stimulate the medial olfactory tracts of male goldfish. Brain Res. 558, 343-347. doi: 10.1016/0006-8993(91)90790-3

Sosulina, L., Meis, S., Seifert, G., Steinhãuser, C., and Pape, H. C. (2006). Classification of projection neurons and interneurons in the rat lateral amygdala based upon cluster analysis. Mol. Cell. Neurosci. 33, 57-67. doi: 10.1016/j.mcn.2006.06.005

Spanswick, D., Renaud, L. P., and Logan, S. D. (1998). Bilaterally evoked monosynaptic EPSPs, NMDA receptors and potentiation in rat sympathetic preganglionic neurones in vitro. J. Physiol. 509(pt 1), 195-209. doi: 10.1111/j.1469-7793.1998.195bo.x
Stacey, N. (1983). Hormones and pheromones in fish sexual behavior. Bioscience 33, 552-556. doi: 10.2307/1309204

Stacey, N., Chojnacki, A., Narayanan, A., Cole, T., and Murphy, C. (2003). Hormonally derived sex pheromones in fish: exogenous cues and signals from gonad to brain. Can. J. Physiol. Pharmacol. 81, 329-341. doi: 10.1139/y03-024

Stacey, N. E., Sorensen, P. W., Van Der Kraak, G. J., and Dulka, J. G. (1989). Direct evidence that $17 \mathrm{a}, 20 \mathrm{~b}$-dihydroxy-4-pregnen-3-one functions as a goldfish primer pheromone: preovulatory release is closely associated with male endocrine responses. Gen. Comp. Endocrinol. 75, 62-70. doi: 10.1016/00166480(89)90008-7

Trudeau, V. L. (1997). Neuroendocrine regulation of gonadotrophin II release and gonadal growth in the goldfish, Carassius auratus. Rev. Reprod. 2, 55-68. doi: 10.1530/ror.0.0020055

Trudeau, V. L., Kah, O., Chang, J. P., Sloley, B. D., Dubourg, P., Fraser, E. J., et al. (2000a). The inhibitory effects of g-aminobutyric acid (GABA) on growth hormone secretion in the goldfish are modulated by sex steroids. J. Exp. Biol. 203, 1477-1485.

Trudeau, V. L., Peter, R. E., and Sloley, B. D. (1991). Testosterone and estradiol potentiate the serum gonadotropin response to gonadotropin-releasing hormone in goldfish. Biol. Reprod. 44, 951-960. doi: 10.1095/biolreprod44.6.951

Trudeau, V. L., Sloley, B. D., and Peter, R. E. (1993). Testosterone enhances GABA and taurine but not N-methyl-D,L-aspartate stimulation of gonadotropin secretion in the goldfish: possible sex steroid feedback mechanisms. J. Neuroendocrinol. 5, 129-136. doi: 10.1111/j.1365-2826.1993.tb00372.x

Trudeau, V. L., Spanswick, D., Fraser, E. J., Lariviere, K., Crump, D., Chiu, S., et al. (2000b). The role of amino acid neurotransmitters in the regulation of pituitary gonadotropin release in fish. Biochem. Cell Biol. 78, 241-259. doi: 10.1139/o99075

Ward, J. H. (1963). Hierarchical grouping to optimize an objective function. J. Am. Stat. Assoc. 58, 236-244. doi: 10.1080/01621459.1963.10500845

Westerman, R., and Wilson, J. A. (1968). The fine structure of the olfactory tract in the teleost Carassius carassius L. Zeitschrift für Zellforschung und Mikroskopische Anatomie 91, 186-199. doi: 10.1007/BF00364310

Wilkie, M. P., Pamenter, M. E., Alkabie, S., Carapic, D., Shin, D. S., and Buck, L. T. (2008). Evidence of anoxia-induced channel arrest in the brain of the goldfish (Carassius auratus). Comp. Biochem. Physiol. C Toxicol. Pharmacol. 148, 355-362. doi: 10.1016/j.cbpc.2008.06.004

Conflict of Interest Statement: The authors declare that the research was conducted in the absence of any commercial or financial relationships that could be construed as a potential conflict of interest.

Received: 31 March 2014; accepted: 11 June 2014; published online: 30 June 2014. Citation: Lado WE, Spanswick DC, Lewis JE and Trudeau VL (2014) Electrophysiological characterization of male goldfish (Carassius auratus) ventral preoptic area neurons receiving olfactory inputs. Front. Neurosci. 8:185. doi: 10.3389/fnins.2014.00185

This article was submitted to Neuroendocrine Science, a section of the journal Frontiers in Neuroscience.

Copyright (c) 2014 Lado, Spanswick, Lewis and Trudeau. This is an open-access article distributed under the terms of the Creative Commons Attribution License (CC BY). The use, distribution or reproduction in other forums is permitted, provided the original author(s) or licensor are credited and that the original publication in this journal is cited, in accordance with accepted academic practice. No use, distribution or reproduction is permitted which does not comply with these terms. 